\title{
Structural Elucidation of Peanut, Sunflower and Gingelly Oils by Using FTIR and ${ }^{1} \mathrm{H}$ NMR Spectroscopy
}

\author{
Veeraprakash Bathini, Suresh Kumar Kalakandan*, Muthukumaran Pakkirisamy and Karthikeyen Ravichandran
}

\section{Veeraprakash Bathini, Suresh Kumar Kalakan- dan*, Muthukumaran Pak- kirisamy and Karthikeyen Ravichandran}

Department of Food Safety Quality Testing Laboratory, Indian Institute of Food Processing Technology, Thanjavur, Tamil Nadu, INDIA.

\section{Correspondence}

\section{Dr.Suresh Kumar Kalakandan}

Department of Food Safety Quality Testing Laboratory, Indian Institute of Food Processing Technology, Thanjavur, Tamil Nadu, INDIA.

Phone no: 91-9655397245, 9976503181

E-mail: sureshkumar.k@iifpt.edu.in, kumaran.bio14@gmail.com

\section{History}

- Submission Date: 21-08-2017;

- Review completed: 03-05-2018;

- Accepted Date: 11-05-2018

DOI : 10.5530/pj.2018.4.126

Article Available online http://www.phcogj.com/v10/i4

\section{Copyright}

(c) 2018 Phcog.Net. This is an openaccess article distributed under the terms of the Creative Commons Attribution 4.0 International license.

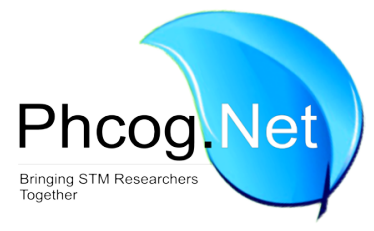

\begin{abstract}
Aims: The present study focused on FTIR and ${ }^{1} \mathrm{H}-\mathrm{NMR}$ spectroscopic methods to assign structural connectivity and purity of the oils. Methods: Non-destructive Fourier Transform Infrared (FTIR) and ${ }^{1} \mathrm{H}$ nuclear magnetic resonance ( $\left.{ }^{1} \mathrm{H}-\mathrm{NMR}\right)$ spectroscopy techniques are used to assign the structural confirmation of the triacylglyceride (TAG) functional component in three different oils namely Sunflower, Peanut, and Gingelly oils respectively. Results: FTIR spectrum shows a very high intense band at $1744 \mathrm{~cm}^{-1}$ associated with the existence of the ester carbonyl functional group $(\mathrm{O}-\mathrm{C}=\mathrm{O})$ and very weak shoulder peak of cis double-bond $(\mathrm{C}=\mathrm{C})$ stretching was noticed at $\sim 1655 \mathrm{~cm}^{-1}$. In ${ }^{1} \mathrm{H}-\mathrm{NMR}$ spectrum shows well resolved chemical shift values in the range 5.3-0.8 ppm corresponding to characteristic group in aliphatic region. Conclusion: Each distinct peak was determined based on chemical shift as well as splitting pattern values. For olefin signal as triplet, tertiary methine protons as singlet, well separated oxymethylene seen as triplet at $\sim 4.2 \mathrm{ppm}$ owing to presence of high electronegative oxygen atom connected to methylene chain gives more deshielding effect. As for bis-allylic, $\alpha$-carbonyl methylene, $\beta$-carbonyl methylene, allylic, saturated methylene along with terminal methyl proton signals are noticed in the span of 2.3-0.8 ppm. A remarkable feature of the spectra is well resolved chemical shift values is clearly support presence of longer hydrocarbon chains. Absence of multiplet coupling peaks and disappearance of signals in down shield region $>5.4$ ppm confirms the absence of trans stereoisomer (E-conformation), aromatic and heterocyclic epoxide compounds.
\end{abstract}

Key words: FTIR, ${ }^{1} \mathrm{H}-\mathrm{NM}$ R, TAG, WHO, Unsaturation, Z-Conformation.

\section{INTRODUCTION}

In recent years a challenging task is to find trace amount of adulterated components in oils and fats at even very low concentration per parts per million to parts per trillion is concern for health. Today, mixing of different substances to formulate completely miscible by using low price raw materials is an increasing in the market (adulteration). ${ }^{1}$ Sometimes contamination may also occur unknowingly either by using refined bleached deodorized palm olefin (RBDPOo), partly hydrolyzed oils (PHOs) or deodorization processing. ${ }^{2}$ According to AOAC Official method and World Health Organisation (WHO) recommendations existence of more quantity of saturated fatty acids increases level of low density lipoprotein (LDL) cholesterol in the blood and trans fatty acid isomer $(>1 \%)$ deleterious cause cardiovascular and cerebrovascular diseases. ${ }^{3}$ As molecular structure point of view triacylglycerols (TAG) which comprises three hydroxy $(\mathrm{OH}-)$ functional groups connected to -carboxylic acid $(\mathrm{COOH})$ of different fatty acid (FA) through ester bond. ${ }^{4}$ However, majority of oils are extracted from different plants or seeds may contain larger number of fatty acid chain length with different degree of unsaturatation (mono or poly) and also may vary position double bonds in hydrocarbon chain. Predominantly, the characteristic features of oils like physicochemical absorption, unsaponifiable and nutritional values are highly depended on the purity of oil substances. ${ }^{5-8}$ At present there are many titration methods as well as spectroscopic techniques are available to identify adulterated materials for quantification in food industry. Among them, gas chromatography mass spectrometry (GC-MS/MS), high-performance liquid chromatography (HPLC), high-performance liquid chromatography mass spectrometry (LC-MS/ MS), High-performance thin layer chromatography (HPTLC), supercritical fluid chromatography etc. ${ }^{9}$ However, in all these equipments are quite labourintensive, time-consuming, requiring extensive experience in sample preparation, involves series of chemical manipulating steps, required high purity of mobile phase, further difficult to analyse the data interpretation. In addition to, many of the chemicals were used in chromatography are caused hazardous to the analyst as well as the environment. ${ }^{10}$ Conversely, in the present study non-destructive FTIR and ${ }^{1} \mathrm{H}-\mathrm{NMR}$ are easy and fast techniques to get information based on distinct peak shift, intensity, 
peak area. Recent times nuclear magnetic resonance (NMR) has become one of the most promising technique to find atomic level structure information (topology) in complex matrices both in solid as well as liquid state, mainly in the area of food processing sector or quality control. ${ }^{11-13}$ As complete structural assignment of individual linking segments provides an advantage to correlate the quantitatively minimum level of the product. Hence, in the present study focused on FTIR and ${ }^{1} \mathrm{H}-\mathrm{NMR}$ spectroscopic methods to assign structural connectivity and purity of the oils. ${ }^{14,15}$

\section{MATERIALS AND METHODS}

Three different oils namely Sunflower, Peanut, and Gingelly oils were chosen for the study. The FTIR experiment was performed on PerkinElmer instrument. Initially dry nitrogen was purged in samples to keep away from interference with atmospheric carbon dioxide along with water vapors. Approximately, $10 \mu \mathrm{L}$ of oil sample was placed on a potassium bromide polished plate. Immediately a uniform thin film was formed on the surface of the potassium bromide plate. ${ }^{11}$ Consequently a high resolution spectra was obtained, hence this method was considered as a neat spectrum because no solvent was used. The sample was scanned at room temperature and collected absorbance frequency data from 600 to $4000 \mathrm{~cm}^{-1}$.

For ${ }^{1} \mathrm{H}-\mathrm{NMR}$ analysis, spectrum was obtained from NMReady- 60 bench top spectrometer with the resonance frequency of $60 \mathrm{MHz}$ in permanent magnet. The sample was prepared in a confirmed within the enclosure of standard $5 \mathrm{~mm}$ NMR tubes (NORELL) and dissolved in $500 \mathrm{uL}$ of deuterated chloroform $\left(\mathrm{CDCl}_{3}\right)$ and solvent peak was noticed at $7.25 \mathrm{ppm}$. Collected the data in the range $0-15 \mathrm{ppm}$ as spectral width and number of scans given for each sample is 128 scans typically $0.06 \mathrm{sec}$ per scan at room temperature. Tetra methyl silane (TMS) used as internal standard reference peak at $0.0 \mathrm{ppm}$. Raw data were exported from the NMReady to be a phase, baseline corrected was done using mestRenova software. All the lines in NMR spectrum was measured in $\delta$ (ppm) with reference chemical shift of standard TMS. ${ }^{16}$

\section{RESULTS AND DISCUSSION}

In this study, the molecular functional group of triacylglyceride linkage (TAGs) was confirmed by using FTIR and ${ }^{1} \mathrm{H}$ NMR spectroscopy.

\section{FTIR spectrum analysis}

In Figure1-3 and Table 1 represents FTIR spectrum of three oils namely Peanut, Sunflower, Gingelly oils respectively. All the three oils spectras were appeared with similar features. Among the peaks, the high intense vibration frequency band was noticed at 1744.07, 1744.28, $1744.24 \mathrm{~cm}^{-1}$ is corresponding to ester carbonyl functional group of triacylglyceride of Peanut, Sunflower, Gingelly oils. Association of three carbonyl functional groups is responsible for higher stretching frequency further evident consist of three carbonyl $(\mathrm{O}-\mathrm{C}=\mathrm{O})$ connectivity.$^{17}$ The important observation (Figure 1-3) is stronger absorption for $\mathrm{C}=\mathrm{O}$, whereas for double bond olefin has shown quite low absorbance band typically at $1652.50,1647.41,1655.30 \mathrm{~cm}^{-1}$ result of double bond $\mathrm{C}=\mathrm{C}$ frequency is not interfere with $\mathrm{C}=\mathrm{O}$ stretching frequency. Unsaturated long chain cis olefinic C-H stretching frequency appeared at $\sim 3008 \mathrm{~cm}^{-1}$ while saturated carbon-carbon symmetrical and asymmetrical stretching observed at $2923,2922,2853 \mathrm{~cm}^{-1}$. However, methylene $\left(\mathrm{CH}_{2}\right)$ symmetrical bending frequency seen in the range 1464-1377 $\mathrm{cm}^{-1}$. Ester bond of C-O stretching was noted around 1160.23,1118.91, $1097.39 \mathrm{~cm}^{-1}$. The appearance of broad band in the range $721.92,721.73,722.00 \mathrm{~cm}^{-1}$ is a loop of cis disubstituted is less symmetry than trans conformation. The spectrum also shows overtone of a weak band at $3481.5,3476.0 \mathrm{~cm}^{-1}$ associated with the glyceride ester carbonyl absorption. The FTIR studies significantly implies variation in the position as well as absorbance of the bands owing to variation in composition of triglyceride fatty acid structures. ${ }^{18}$

\section{${ }^{1} \mathrm{H}$ NMR structural analysis}

In proton NMR study, three oils were subjected to investigate the structural assignment and as well as confirmation of purity. Figure 4-6 shows the proton NMR spectra of three oils recorded in deuterated chloroform at room temperature. Inspection of spectra shows well resolved triplet in deshielded region at $5.39 \mathrm{ppm}$ (Table 2) associated with olefinic protons of double bond signify presence of unsaturated linkages. Very low intense unresolved peak was noticed at $5.03 \mathrm{ppm}$ represents central methine signal of tertiary triglyceride position ( $>\mathrm{CHOCOR}$ ) owing to presence of three bulky substitutes creates more steric effect leads to more shielded shift compare to double bond protons. ${ }^{19}$ The chemical shift values in the range 4.2-3.8 ppm assigned methylene protons of ester connected

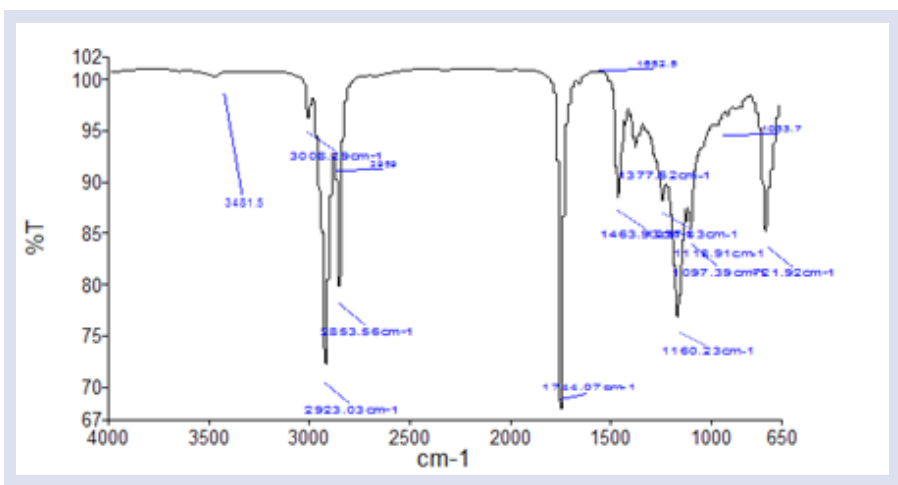

Figure 1: FTIR spectrum of Peanut oil.
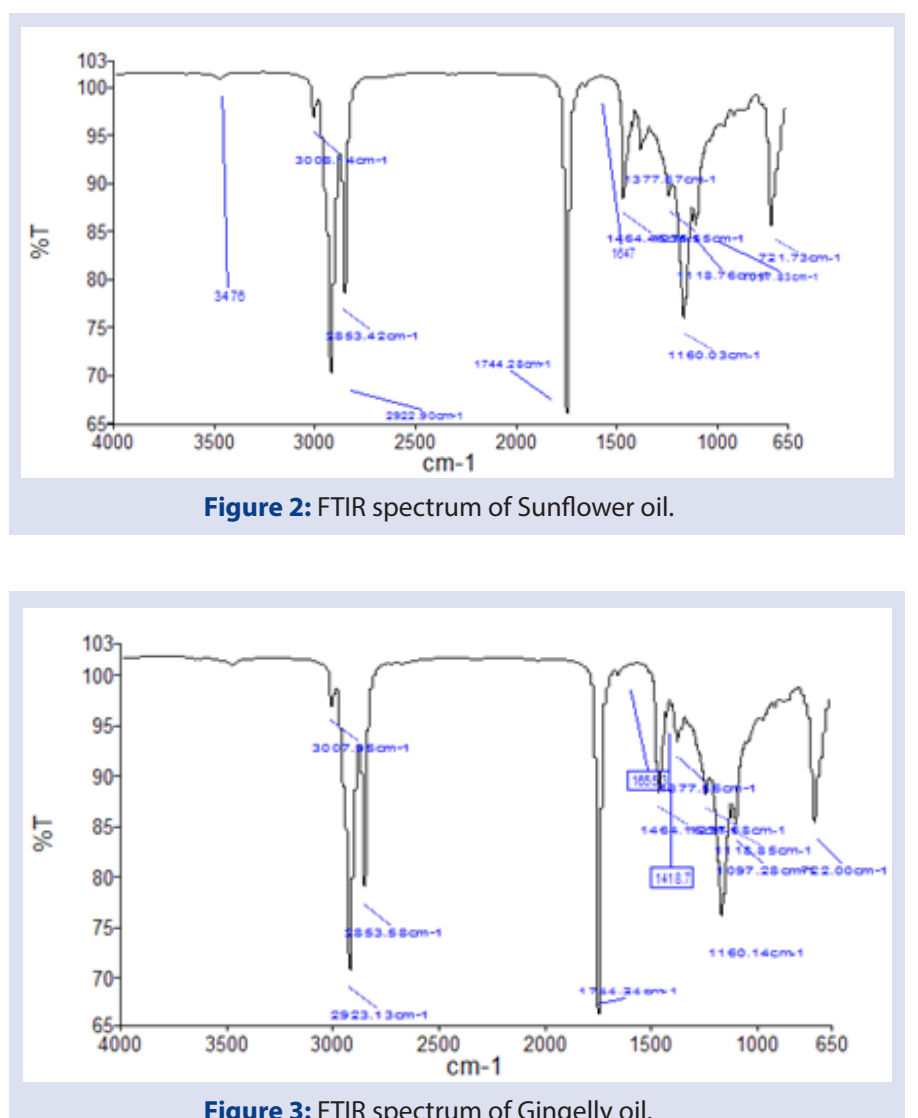

Figure 3: FTIR spectrum of Gingelly oil. 


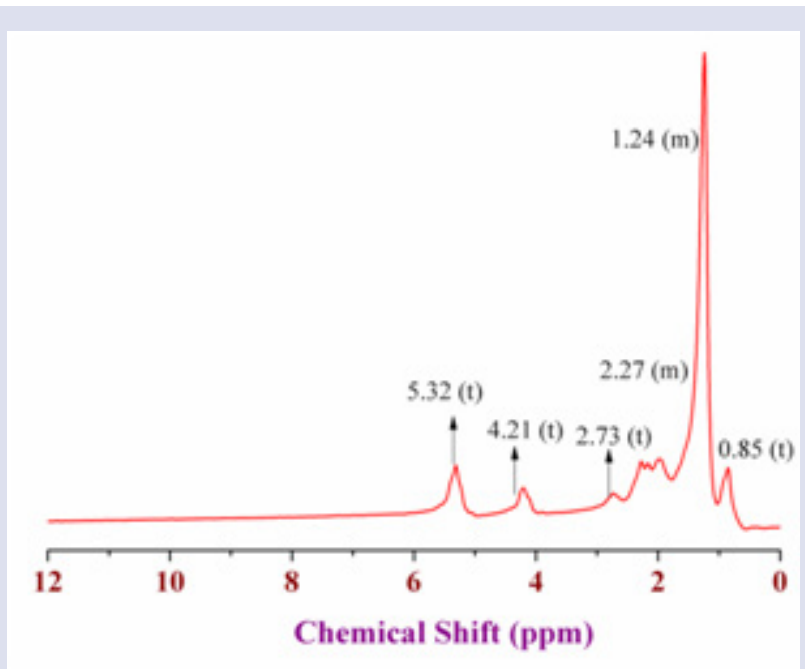

Figure 4: ${ }^{1} \mathrm{H}$ NMR spectrum of Peanut oil recorded in chloroform-(D) at room temperature.

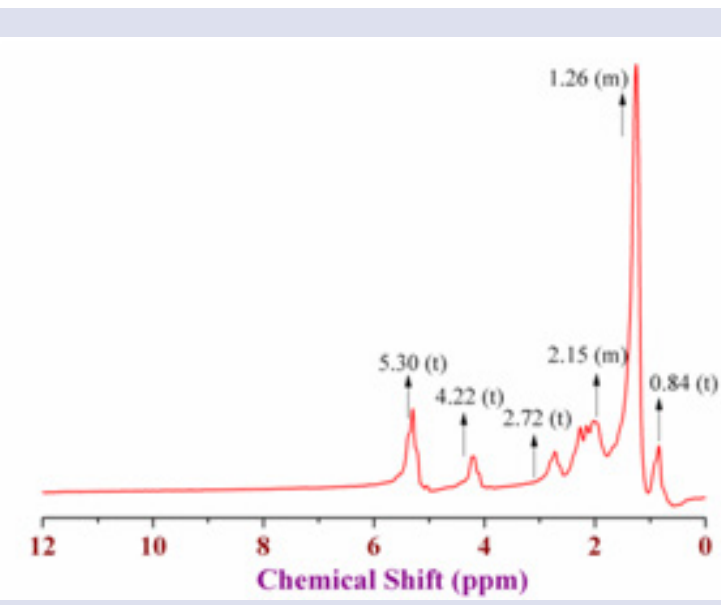

Figure 5: ' $\mathrm{H}$ NMR spectrum of Sunflower oil recorded in chloroform-(D) at room temperature.

Table 1: Major band assignments for the IR Spectra of Peanut, Sunflower and Gingelly oils

\begin{tabular}{|c|c|c|c|}
\hline \multirow{2}{*}{ Attribution } & Peanut Oil & Sunflower Oil & Gingelly Oil \\
\hline & \multicolumn{3}{|c|}{ Wave numbers $\left(\mathrm{cm}^{-1}\right)$} \\
\hline $\begin{array}{l}\text { Symmetric and asymmetric vibration of C-H, H-C-H } \\
\text { and }-\mathrm{CH}_{3}\end{array}$ & $3008.29,2923.03,2853.56$ & $3008.14,2922.90,2853.42$ & $\begin{array}{l}3007.85,2923.13 \\
2853.58\end{array}$ \\
\hline $\begin{array}{l}\text { Elongation vibration of from ester carbonyl groups } \\
\qquad(\mathrm{O}-\mathrm{C}=\mathrm{O})\end{array}$ & 1744.07 & 1744.28 & 1744.24 \\
\hline Double bond $\mathrm{C}=\mathrm{C}$ weak absorption & 1652.50 & 1647.41 & 1655.30 \\
\hline $\begin{array}{l}\text { Symmetric and asymmetric angular deformation } \\
\text { bands of methylene and methyl of alkyl chains }\left(-\mathrm{CH}_{2}^{-} \text {, }\right. \\
\left.\qquad-\mathrm{CH}_{3}\right)\end{array}$ & $1463.91,1377.62$ & $1464,1377.67$ & $1464.11,1418.70$ \\
\hline Ether C-O symmetric stretching & $1160.23,1118.91,1097.39$ & $1160,1118.76$ & $1118.85,1097.28$ \\
\hline Cis- double bond angular deformation & 1003.70 & 1002.6 & 1000.5 \\
\hline angular deformation vinyl loop of cis $\mathrm{HC}=\mathrm{CH}$ & 721.92 & 721.73 & 722.00 \\
\hline
\end{tabular}

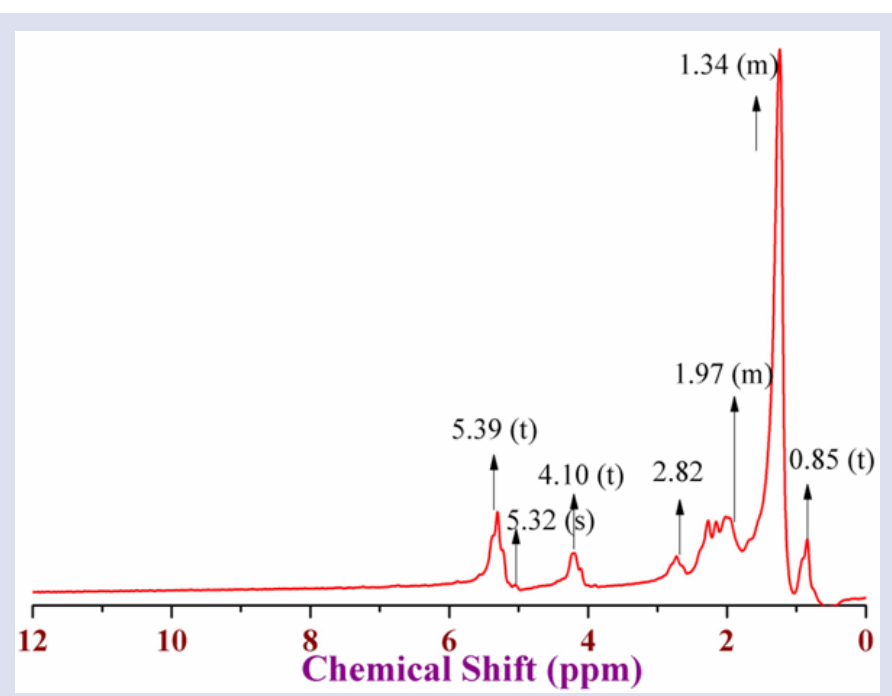

Figure 6: ' $\mathrm{H}$ NMR spectrum of Gingelly oil recorded in chloroform(D) at room temperature. triglyceride molecule. Bisallyic $\left(=\mathrm{CH}-\mathrm{CH}_{2}-\mathrm{CH}=\right)$ and adjacent to carbonyl protons $\left(\mathrm{O}-\mathrm{C}=\mathrm{O}-\mathrm{CH}_{2}-\right.$ ) were seen typically at 2.8-2.1 ppm (allyl, bisallylic, trisallylic). The remaining more number of methylene protons of adjacent double bond appeared at $1.38-1.26$ as multiplet $(\mathrm{m})$ peak. Terminal methyl shows approximately at $0.8 \mathrm{ppm}$ as triplet. ${ }^{20}$

By integration of each individual peak in spectrum further may utilise to quantify ratios of saturated and unsaturated fatty acids in TAGs profile. The appearance of triplet peak at $5.3 \mathrm{ppm}(\mathrm{Z}$-vinyl $\mathrm{CH}$ ) further confirms absence of epoxide formation through free radical mechanism. ${ }^{21}$ It is known that olefinic protons are more susceptible site to undergo oxidation conversion $\mathrm{C}=\mathrm{C}$ in presence of oxygen under high temperature. Further, peak appeared at $5.3 \mathrm{ppm}$ as district triplet due to arrangement of double bonds as cis $(Z)$ conformation in hydrocarbon chain..$^{22}$ Comparison of NMR data of all the three oils (Table 2) a slight variation in chemical shift as well as intensity. Remarkably bis-allylic position chemical shift values in sunflower oil is low intense than peanut and gingelly oils. It may be due to slightly lower in saturated fatty acid content. ${ }^{23}$ The spectrum (Figure 4-6) clearly support presence of different chemical environment. In all the cases, lines appeared in lower chemical shift region (aliphatic region) 5.3 to $0.8 \mathrm{ppm}$ support protons of oleic, linoleic, linolenic and saturated fatty acids respectively. ${ }^{24}$ 
Table 2: Solution proton NMR Chemical shifts of different protons, s-singlet, $d$-doublet, t-triplet, m-multiplet peaks.

\begin{tabular}{|c|c|c|c|c|}
\hline \multirow{2}{*}{ NMR solvent } & Peanut Oil & Sunflower Oil & Gingelly Oil & Assignment \\
\hline & \multicolumn{3}{|c|}{${ }^{1} \mathrm{H}$ NMR Chemical Shift (ppm) } & \\
\hline \multirow{6}{*}{$\begin{array}{l}\text { Chloroform } \\
\left(\mathrm{CD}_{3} \mathrm{Cl}\right)\end{array}$} & $5.32,5.30,5.06(t)$ & $5.38,5.30,5.23(\mathrm{t})$ & $5.39,5.32,5.22(\mathrm{t})$ & $-\mathrm{HC}=\mathrm{CH}-$ olefins $(\mathrm{Z}-$ form $)$ \\
\hline & $4.21-3.91(\mathrm{t})$ & $4.22,4.10(\mathrm{t})$ & $4.21-4.10,3.83(\mathrm{~m})$ & $\begin{array}{l}-\mathrm{CH}_{2}-,-\mathrm{CH}-\text { of oxy methylene } \\
\text { triaceylglyceride }\end{array}$ \\
\hline & $2.73(\mathrm{t})$ & $2.72,2.39,2.28,2.15(\mathrm{t})$ & $2.82,2.73,2.27(\mathrm{t})$ & $-\mathrm{CH}_{2}-$ of bisallylic \\
\hline & $2.27-2.15(\mathrm{~m})$ & $2.04,1.95,1.69(\mathrm{~m})$ & $1.97(\mathrm{~m})$ & $\begin{array}{c}-\mathrm{CH}_{2}-\mathrm{CH}_{2}-\mathrm{CH}_{2} \text { of allylic \& alpha } \\
\text { methylene }\end{array}$ \\
\hline & $1.32-1.24(\mathrm{~m})$ & $1.38,1.26(\mathrm{~m})$ & $1.34,1.24(\mathrm{t})$ & $\begin{array}{c}-\mathrm{CH}_{2}-\mathrm{CH}_{2}-\mathrm{CH}_{2} \text { of methylene alkyl } \\
\text { chain }\end{array}$ \\
\hline & $0.85(t)$ & $0.98,0.84,0.74(\mathrm{t})$ & $0.85(\mathrm{t})$ & $-\mathrm{CH}_{3}$ of terminal methyl \\
\hline
\end{tabular}

\section{CONCLUSION}

In this work, we attempted to analyse TAGs profile of fatty acids in three different oils by using FTIR and ${ }^{1} \mathrm{H}$ NMR. The analysis confirms the presence of functional groups in the Peanut, Sunflower and Gingelly oils all absorptions in the region $722-3000 \mathrm{~cm}^{-1}$ corresponding to $\mathrm{C}-\mathrm{H}$, $\mathrm{H}-\mathrm{C}-\mathrm{H}-\mathrm{CH}_{3}, \mathrm{C}-\mathrm{O}$ and $\mathrm{O}-\mathrm{C}=\mathrm{O}, \mathrm{C}=\mathrm{C}$ with well resolved stretching frequencies was noticed. In proton NMR spectra of olefin protons clearly separated from glyceride methylene protons depicted at $5.3 \mathrm{ppm}$ whereas bis-allylic as triplet seen at $2.82-2.73 \mathrm{ppm}$. The absence of doublet of doublet or multiplet peaks and appearance in shielded region in the span of 5.30-0.8 ppm reveals the double bonds both in mono and poly unsaturated fatty acids retains in $\mathrm{Z}$ or cis conformation. Further NMR spectrum clearly evident disappearance of signals for epoxide ring, aldehyde, mono and diacylglycerol protons as a result of more oxidative stability of all the three oils. The slight variation of peak values both in FTIR and proton NMR result of variation of content between saturated and unsaturated fatty acids. The used methodology is an interesting and quite valuable for the authentication of edible oils both in food industry, quality control as well as human health. Its main advantage is simplicity, speed, less time consume high-sensitivity and no require for sample pre-treatment.

\section{ACKNOWLEDGEMENT}

The authors are thankful to Dr. C. Anandharamakrishnan, Director, Indian Institute of Food Processing Technology, Thanjavur, Tamil Nadu, India for providing all the facilities to conduct this work and also thankful to the members of Department of Food Safety and Quality Testing division of for their support.

\section{CONFLICT OF INTEREST}

There are no conflicts of interest.

\section{ABBREVIATION USED}

FT-IR: Fourier Transform Infrared; ${ }^{1}$ H-NMR: Proton Nuclear Magnetic Resonance.

\section{REFERENCES}

1. David IE, Victoria LB, Warwick BD, William JA, Alexander PG, Royston G. Fingerprinting food: current technologies for the detection of food adulteration and contamination. Chem Soc Rev. 2012;41(17):5706-27.

2. Moore JC, Spink J, Lipp M, Development and application of a database of food ingredient fraud and economically motivated adulteration. J Food Sci. 2012;77:(4)118-26.

3. Mueller, T. Extra Virginity: The Sublime and Scandalous World of Olive Oil, Atlantic Books, London, 2013.
4. Crews C, Hough P, Godward J, Brereton P, Lees M, Guiet S, Winkelmann W. Study of the main constituents of some authentic hazelnut oils. J Agric Food Chem. 2005;53(12):4843-52.

5. Lin SW, Gunstone FD. Vegetable Oils in Food Technology, Blackwell Publishing, Oxford, U.K. 2002;59-97.

6. Zahoor U, Mohamad AB, Zakaria M. Characterization of Waste Palm Cooking Oil for Biodiesel Production, International Journal of Chemical Engineering and Applications. 2014;5(2):134-7.

7. Laakso P. Analysis of Triacylglycerols-Approaching the Molecular Composition of Natural Mixtures, Food Rev. Int, 1996;12(2):199-250.

8. Guillén MD, Ruiz A. Monitoring the oxidation of unsaturated oils and formation of oxygenated aldehydes by proton NMR. Eur J Lipid Sci Technol. 2005;107(1):3647.

9. Buchgraber $M$, Ulberth $F$, Emons $H$, Anklam E. Triacylglycerol Profiling by Using Chromatographic Techniques. Eur J Lipid Sci Technol. 2004;106(9):621-48.

10. Ribeiro APB, Basso RC, Grimaldi R, Gioielli LA, Guaraldo LA. Instrumental Methods for the Evaluation of Interesterified Fats. Food Anal. Methods, 2009;2(4):282-302

11. Rohman A, Man Y. Fourier transform infrared (FTIR) spectroscopy for analysis of extra virgin olive oil adulterated with palm oil, Food Research International, 2010;43(3):886-92.

12. Guillen MD, Cabo N. Infrared spectroscopy in the study of edible oils and fats, Journal of the Science of Food and Agriculture. 1997;75(1):1-11.

13. Rohman A, Man Y. Fourier transform infrared (FTIR) spectroscopy for analysis of extra virgin olive oil adulterated with palm oil, Food Research International, 2010;43: 886-892

14. Knothe G, Dunn RO. Dependence of oil stability index of fatty compounds on their structure and concentration and presence of metals, J Am Oil Chem Soc. 2003;80(10):1021-26.

15. Barison A, Werner Pereira da Silva C, Campos FR, Simonelli F, Lenzb CA, Ferreirac AG. A simple methodology for the determination of fatty acid composition in edible oils through ${ }^{1} \mathrm{H}$ NMR spectroscopy. Magn Reson Chem. 2010;48(8):642-50.

16. Lie Ken Jie MSF, Mustafa J, High-resolution nuclear magnetic resonance spectroscopy: Applications to fatty acids and triacylglycerols, Lipids. 1997;32(10):1019-34.

17. Pimentel MF. Infrared spectroscopy and multivariate calibration to monitor stability quality parameters of biodiesel. Microchemical Journal. 2010;96(1):126-31.

18. Lerma Garcia MJ, Ramis RG, Herrero-Martinez JM, Simo-Alfonso EF. Authentication of extra virgin olive oils by Fourier-transform infrared spectroscopy. Food Chem. 2010;118(1):78-83.

19. Castejón, D,Fricke P, Camber MI, Herrera A. Automatic ${ }^{1} \mathrm{H}-\mathrm{NMR}$ Screening of Fatty Acid Composition in Edible Oils. Nutrients. 2016;8(2):1-10.

20. Crews C, Hough P, Godward J, Brereton P, Lees M, Guiet S, Winkelmann W. Study of the main constituents of some authentic hazelnut oils. J Agric Food Chem. 2005;53(12):4843-52.

21. Gurdeniz G, Ozen B. Detection of adulteration of extra-virgin olive oil by chemometric analysis of mid-infrared spectral data. Food Chem. 2009;116(2):519-25.

22. Guillen M D, Ruiz A. Edible oils: discrimination by ${ }^{1} \mathrm{H}$ nuclear magnetic resonance. J Sci Food Agric. 2003;83(4):338-46.

23. Guillén M D, Ruiz A. Study by proton nuclear magnetic resonance of the thermal oxidation of oils rich in oleic acyl groups. Journal of the American Oil Chemists Society. 2005;82:(5)349-55.

24. Joseph J, Baker C, Mukkamala S. Chemical shifts and lifetimes for nuclear magnetic resonance (NMR) analysis of biofuels. Energy and Fuels. 2010;24(9): 5153-62. 
GRAPHICAL ABSTRACT

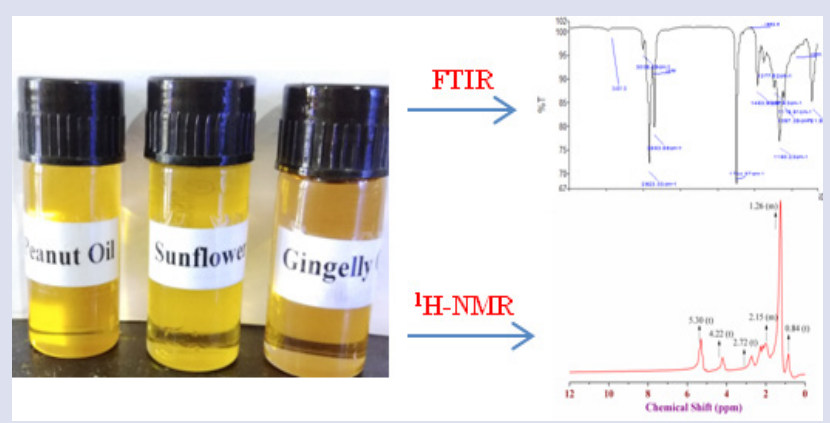

\section{SUMMARY}

- Today, mixing of different substances to formulate completely miscible components by using low price raw materials is an increasing in the market particularly in oils and fats adulteration.

- In the Present study a non-destructive FTIR and 1H-NMR methods are an easy and fast techniques to get structural information based on distinct peak values, peak shift, peak intensity, peak integration and peak area.

- The used methodology is quite valuable for the authentication of edible oils both in food industry, quality control as well as human health.

\section{ABOUT AUTHORS}

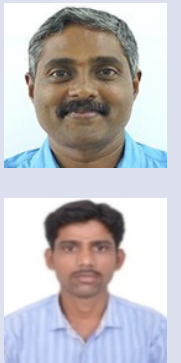

Dr. K. Suresh Kumar: Associate Professor and Head i/c of Department of Food Safety and Quality Testing, Indian Institute of Food Processing Technology, Thanjavur, Tamil Nadu, India.

Bathini Veeraprakash: Senior Research Fellow, Department of Food Safety and Quality Testing, Indian Institute of Food Processing Technology, Thanjavur, Tamil Nadu, India. He completed MSc degree (2009) in Organic Chemistry from the Sri Venkateswara University, Tirupati, Andhra Pradesh, India. He received Prof. Dr. S. Jayarama Reddy Gold Medal. He is also the recipient of the CSIR-research fellowship from Government of India for Doctoral studies.

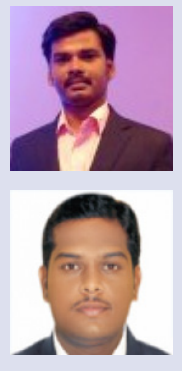

Dr. P. Muthukumaran: Senior Research Fellow, Department of Food Safety and Quality Testing, Indian Institute of Food Processing Technology, Thanjavur, Tamil Nadu, India.

Dr. R. Karthikeyan: Technical Assistant, Department of Food Safety and Quality Testing, Indian Institute of Food Processing Technology, Thanjavur, Tamil Nadu, India.

Cite this article: Veeraprakash B, Kumar SK, Muthukumaran P, Karthikeyan R. Structural Elucidation of Peanut, Sunflower and Gingelly Oils by Using FTIR and ${ }^{1} H$ NMR Spectroscopy. Pharmacog J. 2018;10(4):753-7. 